\title{
The effect of body weight in infants undergoing ventricular septal defect closure: A report from the Nationwide Japanese Congenital Surgical Database
}

Taku Inohara, MD, PhD, ${ }^{\text {a,b,h }}$ Nao Ichihara, MD, MPH, PhD, ${ }^{\text {ch }}$ Shun Kohsaka, MD, PhD, ,c,h Hiroaki Miyata, $\mathrm{PhD},{ }^{\mathrm{c}, \mathrm{d}}$ Yasutaka Hirata, $\mathrm{MD}, \mathrm{PhD},{ }^{\mathrm{e}, \mathrm{h}}$ Arata Murakami, MD, PhD,, h Hideyuki Shimizu, MD, $\mathrm{PhD},{ }^{\mathrm{g}}$ and Ryo Aeba, $\mathrm{MD}, \mathrm{PhD}^{\mathrm{g}}$

\section{ABSTRACT}

Objective: In infants with ventricular septal defect (VSD) who undergo surgical intervention, body weight, along with age, is frequently thought to be the decisive predictor of morbidity and mortality after surgery; however, its information on quantitative risk assessment is limited.

Methods: All infants ( $<1$ year old) with a fundamental diagnosis of VSD who underwent surgical VSD closure or pulmonary artery banding between 2012 and 2016 were identified from the Japan Cardiovascular Surgery Database Congenital Section. The outcome of interest was a composite end point of all-cause death and major complications within 30 days after surgery. We evaluated the association between body weight at surgery and composite end point using logistic regression models.

Results: A total of 4947 cases were analyzed (median age, 125; interquartile range [IQR], 79-193 days; median body weight, 4.94 [IQR, 4.00-6.00] kg), including 4310 cases $(87.1 \%)$ treated with surgical VSD closure and 637 $(12.9 \%)$ treated with pulmonary artery banding. The surgical course was uncomplicated in $94.2 \%$ of cases, $23(0.5 \%)$ died, and $283(5.7 \%)$ experienced major complications. The risk of the composite end point was higher along with lower body weight (adjusted odds ratio, 1.56 for every $-1 \mathrm{~kg} ; 95 \%$ confidence interval, 1.30-1.88; $P<.001$ ) and plateaued at body weight of approximately $>4.5 \mathrm{~kg}$ via smoothing spline curve. Importantly, cases with approximately $<4.5 \mathrm{~kg}$ of body weight had higher predicted risk regardless of age.

Conclusions: Surgical intervention for infants with VSD was safely performed in contemporary practice; however, caution is warranted in lower body weight infants, particularly for infants with approximately $<4.5 \mathrm{~kg}$. (J Thorac Cardiovasc Surg 2019;157:1132-41)

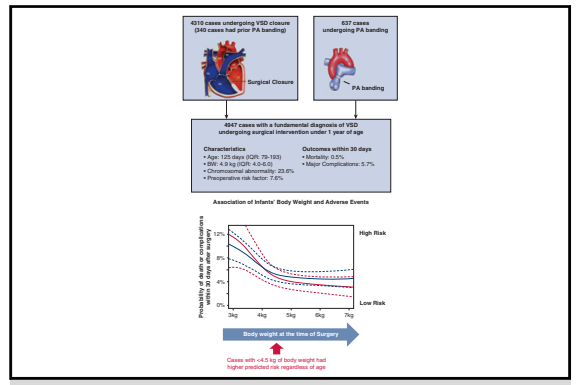

Spline relationship between body weight at surgery and adverse events.

\section{Central Message}

Surgical intervention for infants with VSD was safely performed in a current practice; however, caution is warranted in lower body weight infants (particularly for infants of approximately $<4.5 \mathrm{~kg}$ body weight).

\section{Perspective}

This work represents one of the largest studies to assess the association between body weight and clinical outcome after surgery in infants with VSD who undergo surgical intervention and shows the robust relationship with the specific threshold of approximately $4.5 \mathrm{~kg}$ body weight. These findings are useful for patient counseling and aids in facilitating understanding of the risk of surgery.

See Commentaries on pages 1142 and 1144 .

\footnotetext{
From the Departments of ${ }^{\mathrm{a}}$ Cardiology and ${ }^{\mathrm{d}}$ Health Policy and Management, and ${ }^{\mathrm{g}}$ Division of Cardiovascular Surgery, Keio University School of Medicine, Tokyo, Japan; ${ }^{b}$ Duke Clinical Research Institute, Duke University Medical Center, Durham, NC; Departments of ${ }^{\mathrm{C}} \mathrm{Healthcare}$ Quality Assessment and ${ }^{\mathrm{e}} \mathrm{Cardiac}$ Surgery, The University of Tokyo, Tokyo, Japan; ${ }^{\mathrm{f}}$ Kanazawa Cardiovascular Hospital, Kanazawa, Japan; and the ${ }^{\mathrm{h} J a p a n}$ Cardiovascular Surgical Database.

The present study was supported by the Miyata Cardiac Research Promotion Foundation. The funders had no role in the conduct of the study; in the collection, management, analysis, and interpretation of the data; or in the preparation or approval of the report.

Received for publication June 20, 2018; revisions received Nov 3, 2018; accepted for publication Nov 6, 2018.

Address for reprints: Shun Kohsaka, MD, PhD, Department of Cardiology, Keio University School of Medicine, 35 Shinanomachi, Shinjuku-ku, Tokyo, Japan 160-8582 (E-mail: sk@z3.keio.jp).

$0022-5223 / \$ 36.00$

Copyright $(\odot) 2018$ by The American Association for Thoracic Surgery

https://doi.org/10.1016/j.jtcvs.2018.11.111
}

Ventricular septal defect (VSD) is the most common form of congenital cardiac abnormality worldwide, with an incidence of 2.62 per 1000 live births. ${ }^{1}$ Among these, approximately $50 \%$ of infants and children require surgical closure, ${ }^{2,3}$ making it the most commonly performed pediatric cardiac surgical procedure. Furthermore, the advancement in surgical devices, techniques, and equipment has enabled a shift toward repairing defects

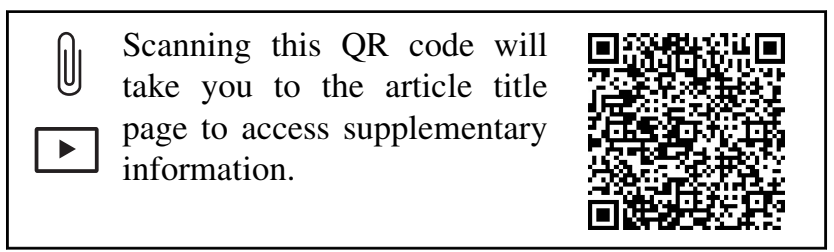




\section{Abbreviations and Acronyms \\ $\mathrm{CI}=$ confidence interval \\ $\mathrm{IQR}=$ interquartile range \\ JCVSD $=$ Japan Cardiovascular Surgery Database \\ $\mathrm{OR}=$ odds ratio \\ $\mathrm{PAB}=$ pulmonary artery banding \\ VSD $=$ ventricular septal defect}

earlier. At present, early closure of VSD is considered to reduce the time required for therapy to prevent or treat heart failure and minimize exposure to increased pulmonary pressure. ${ }^{4-8}$ In addition, as an alternative to direct defect closure, interim palliative procedures such as pulmonary artery banding (PAB) to reduce pulmonary blood flow for smaller infants have been shown to influence the outcome. ${ }^{9}$

Optimizing patient selection and timing for surgical intervention on VSD is obscured by a lack of a standardized definition of procedural variables and the paucity of multiinstitutional studies. A small single-center study reported that young age $(<6$ months) and low body weight are the major risk factors for complication. ${ }^{7}$ However, the contemporary outcomes in infants with VSD have not been studied extensively. ${ }^{9}$ As a consequence, the decision of when to offer corrective surgery for infants born with VSD is variable, and it remains challenging to define the patient parameters that provide the greatest probability of a successful outcome while minimizing the risk of complication. We sought to: (1) evaluate the association of patient body weight and outcomes in patients with VSD requiring surgical intervention in the first year of life; (2) determine an empiric threshold of body weight at surgery with acceptable risks on the basis of a contemporary national surgical database in Japan; and (3) investigate the clinical outcome in patients with VSD requiring a palliative approach with $\mathrm{PAB}$.

\section{METHODS}

\section{Data Source}

The Japan Cardiovascular Surgery Database (JCVSD) Congenital Section was established in 2008. It is a prospective Japanese nationwide multicenter database to assess surgical outcomes after congenital heart surgery. ${ }^{10,11}$ The JCVSD currently collects clinical information from 121 Japanese heart institutions specializing in congenital heart disease, covering all congenital heart surgery programs in Japan. Variables and definitions used in the JCVSD are almost identical to those of the Society of Thoracic Surgeons-European Association for Cardiothoracic Surgery database for congenital heart surgery (definitions are available online at http://sts.org). The JCVSD constructed the software for Web-based data collection system, and each data manager in the participating hospitals submits data via computer through this system. The registration of JCVSD is mandated for the application of cardiovascular surgical board/institutional certification as well as its renewal. Validation methods such as auditing, site visiting, and education are routinely performed.
Each participating hospital received the appropriate approval from the respective institutional review board.

\section{Study Population}

Figure 1 shows a summary of the process of identifying the study population. To account for patients who underwent PAB but did not have subsequent VSD closure, all patients with a fundamental diagnosis of VSD who underwent surgical VSD closure or PAB between January 2012 and December 2016 younger than 1 year of age were identified $(\mathrm{n}=5469)$. This initially identified study cohort included infants with all types of VSD (type 1, type 2, type 3, type 4, and Gerbode type) as well as multiple VSDs. Of these, patients with extracardiac malformation $(n=499)$ and patients with body weights that were apparent outliers $(n=23)$ were excluded. As a result, the final cohort included 4947 cases (main cohort). The final cohort included infants younger than 1 year of age with a fundamental diagnosis of VSD who: (1) underwent surgical 1-stage VSD closure; (2) had a history of PAB and underwent surgical VSD closure; and (3) underwent PAB regardless of subsequent VSD closure. Secondary diagnoses and procedures that were performed in 2012 are summarized in Tables E1 and E2. Because registration to the JCVSD is on a surgical case basis, patients who underwent PAB and subsequent surgical VSD closure were counted as 2 cases. Subsequently, to perform a sensitivity analysis, we identified patients who underwent surgical VSD closure without previous PAB (VSD cohort; $n=3970$ ). For an exploratory analysis, we extracted data of patients who underwent $\mathrm{PAB}$ from the main cohort (PAB cohort; $\mathrm{n}=637$ ).

\section{Outcomes}

The outcome of interest was the composite of all-cause death (recorded in the database either as death at 30 days after surgery or death at discharge) and major complications within 30 days after surgery. Major complications included unplanned reoperation, arrhythmia requiring permanent pacemaker implantation or cardioversion, cardiac arrest, circulatory instability requiring mechanical support (intra-aortic balloon pump, extracorporeal membrane oxygenation, or ventricular assist device), pulmonary hypertensive crisis, acute renal failure requiring hemodialysis or hemofiltration persisting at discharge, respiratory failure requiring tracheotomy, chylothorax, wound infection (deep wound infection or mediastinitis), phrenic nerve paralysis, and neurological deficit persisting at discharge. The definitions of major complications were in accordance with those in the Society of Thoracic Surgeons-European Association for Cardiothoracic Surgery database for congenital heart surgery.

\section{Data Completeness}

The National Clinical Database ensures data traceability by tracking the staff who approves the data along with data entry personnel at the participating institutions for the JCVSD. It also validates data consistency via random inspections of participating institutions. Data were cleaned and maintained independently by the Department of Healthcare Quality Assessment, at the University of Tokyo, Tokyo, Japan, which produces annual site-specific reports to JCVSD participant hospitals for outcome analyses and quality improvement. The registry uses an electronic Web-based data collection system that does not permit missingness for most of the data components at registration. Therefore, the prevalence of missing data is extremely low. ${ }^{12}$

\section{Statistical Analysis}

The study cohort was divided into 2 groups according to body weight (above vs below median), and baseline characteristics were compared between groups. We calculated median with interquartile range (IQR) for continuous variables in each group and compared them using Student $t$ test. Categorical variables are reported as counts and percentages, and differences among groups were assessed using Pearson $\chi^{2}$ test. 


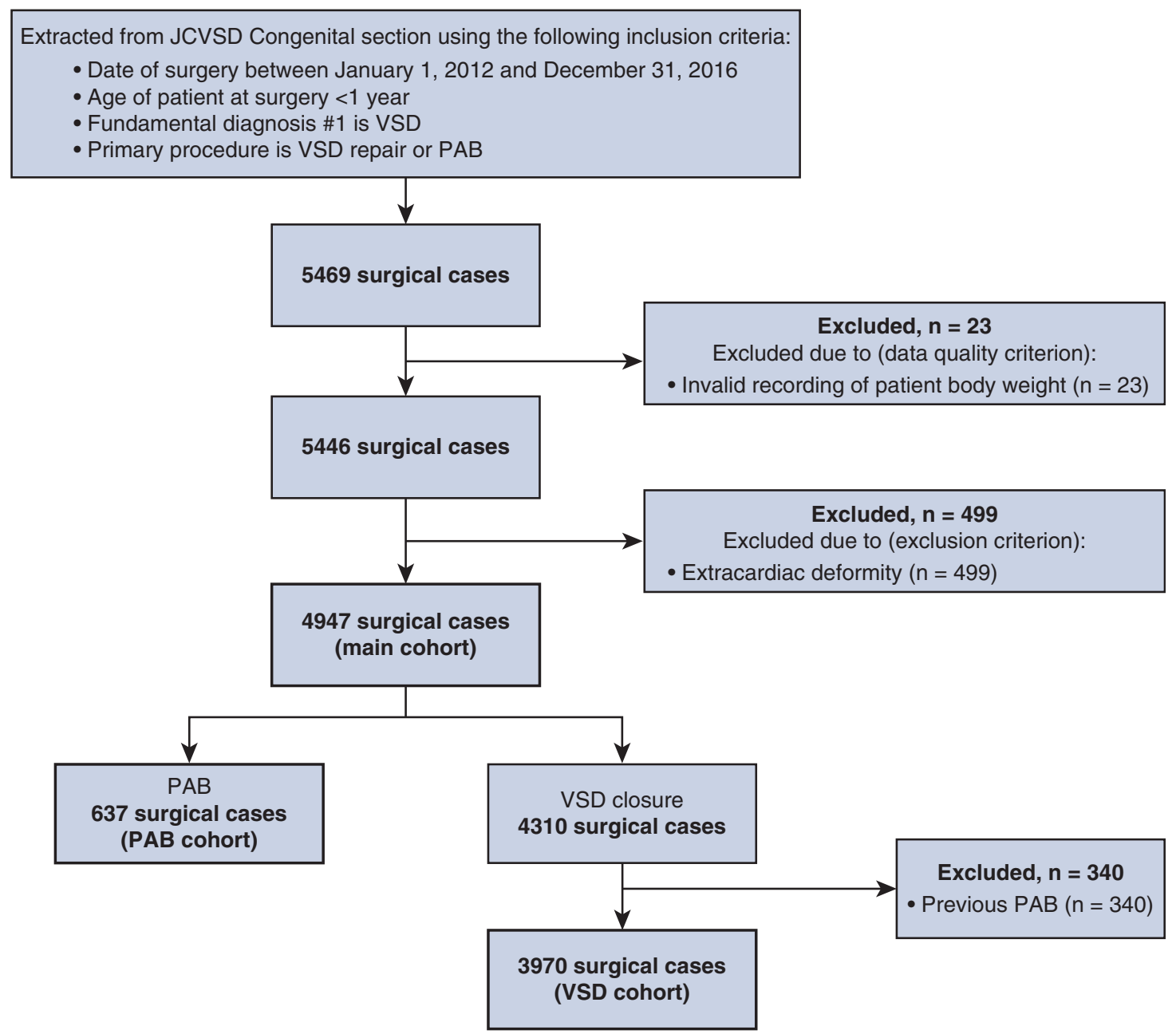

FIGURE 1. Study cohort creation. JCVSD, Japan Cardiovascular Surgery Database; VSD, ventricular septal defect; $P A B$, pulmonary artery banding.

In the main cohort, correlation between risk of complications or death and body weight was summarized using cubic splines with a logit link function. The degree of freedom and smoothing parameter were manually chosen to summarize the features of the data while avoiding overfitting. Then, to determine whether body weight was independently associated with the composite end point, a generalized additive model was used in which body weight was transformed using cubic spline as well as linear spline whereas the other independent variables were simply multiplied by the coefficients. Covariates for adjustment included the following variables: sex, age at operation $<28$ days (Figure E1), early delivery, chromosomal abnormality, history of previous surgery (initial surgery or not), any of predefined preoperative risk factors (Online Data Supplement), home oxygen therapy, preoperative use of angiotensin-converting enzyme inhibitor, preoperative use of digitalis, preoperative use of diuretics, preoperative use of intravenous drugs, operative status (elective vs nonelective), and transfusion. When body weight was transformed using linear spline, measurements $<3.0 \mathrm{~kg}$ were replaced with $3.0 \mathrm{~kg}$ and those $>5.0 \mathrm{~kg}$ were replaced with $5.0 \mathrm{~kg}$, on the basis of the adjusted relationship between body weight and composite end point described in Figures 2 and 3. Adjusted associations were reported as odds ratio (OR) and $95 \%$ confidence interval (CI). As a sensitivity analysis, the same analyses as we did in the main cohort were duplicated in the VSD cohort. In the $\mathrm{PAB}$ cohort, crude outcome was presented for an exploratory purpose. No multivariate modeling was performed because of its small sample size.
In the main cohort, to visualize the combined effect of body weight and age at surgery, we developed a model predicting composite end point using a general additive model with tensor product smooth of body weight and age. Tensor transformation allows smoothing of the combined effect of 2 dependent variables and does not require assumptions of effect linearity or independency between 2 independent variables. Other predictors used were those used for the logistic regression model, with "age at operation $<28$ days" replaced with the corresponding continuous variable. This model was used to predict the risk of the composite end point in each patient, which was then visualized as different colors in a scatterplot of age and body weight at surgery.

No candidate variables in the main cohort had any missingness except $\operatorname{sex}(n=2)$ and early delivery $(n=116)$, for which "unknown" is allowed in the database. Data missing in the multivariate models were addressed using single imputation: "girl" for sex and "no" for early delivery. All statistical analyses were performed by the National Clinical Database using $\mathrm{R}$, version 3.4.4 (R Foundation for Statistical Computing, Vienna, Austria) and JMP Pro, version 13.2.1 (SAS Institute Inc, Cary, NC). All $P$ values are 2-sided, and $P<.05$ was considered statistically significant.

\section{RESULTS}

The final study patients comprised 4947 cases: 4310 cases $(87.1 \%)$ underwent surgical VSD closure and $637(12.9 \%)$ 


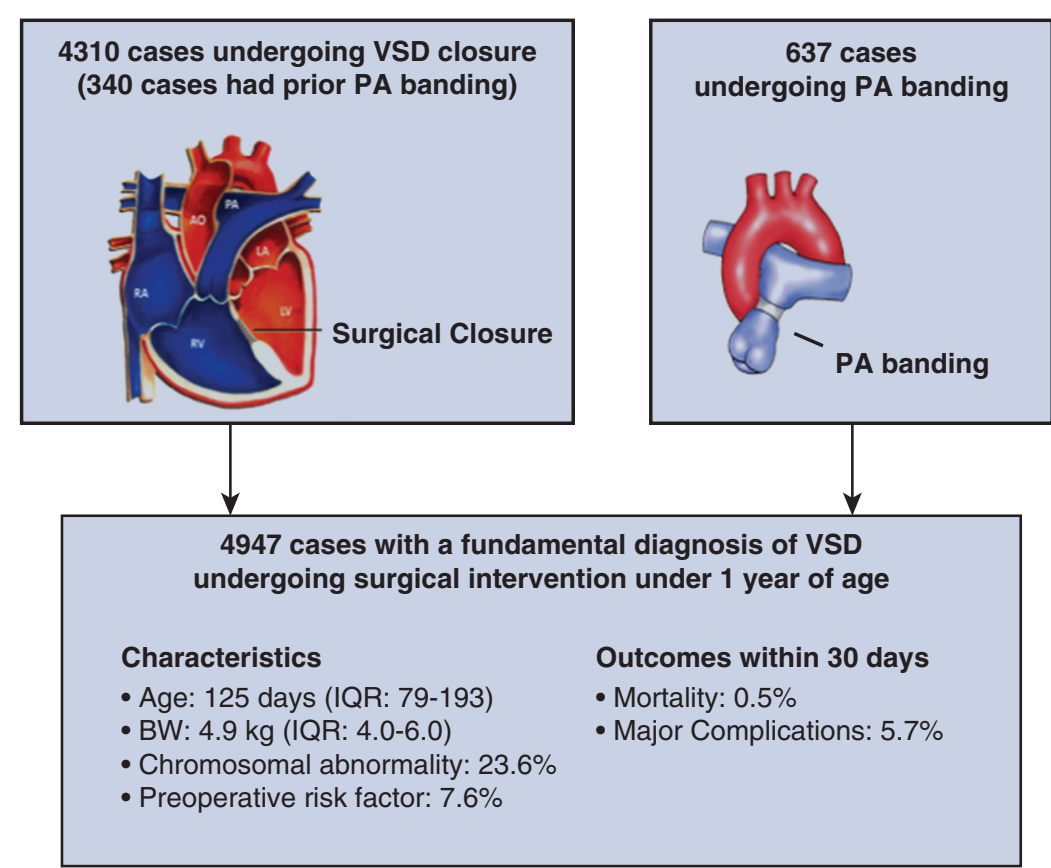

Association of Infants' Body Weight and Adverse Events

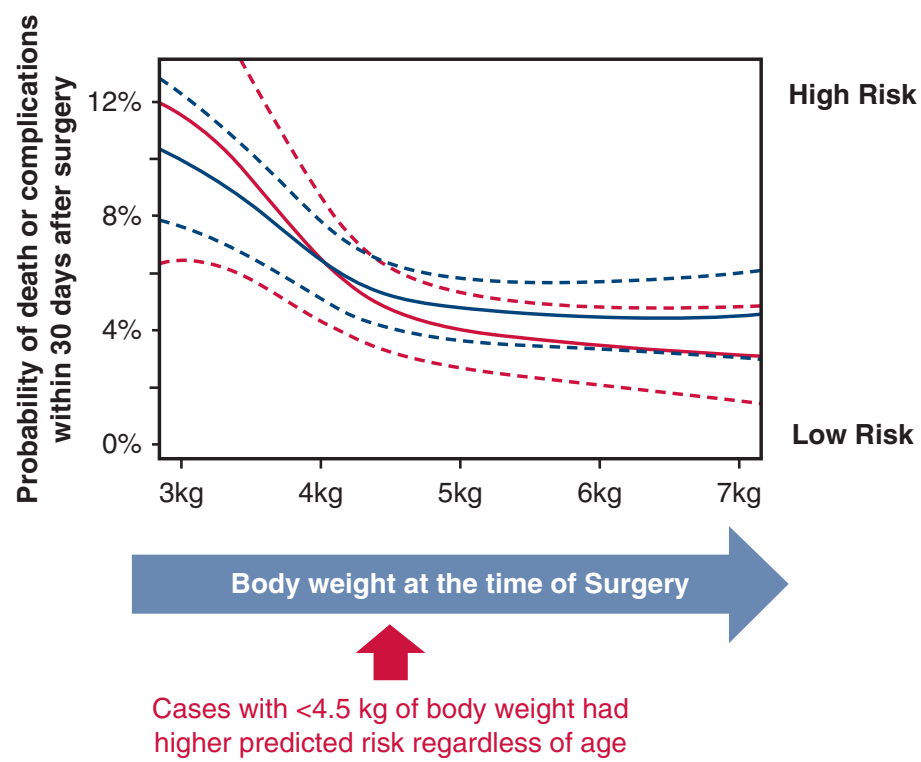

FIGURE 2. Spline relationship between body weight $(B W)$ at surgery and composite end point in the main cohort. In infants with ventricular septal defect $(V S D)$ requiring surgical intervention within 1 year of their life, lower body weight at the time of surgery was significantly associated with increased risks of the composite end point, particularly for infants with approximately $<4.5 \mathrm{~kg}$ body weight. Estimated smoothing spline curves represent the relationship between body weight and the rate of composite end point of all-cause death and major complications within 30 days after surgery in the main cohort. Solid blue and red lines represent unadjusted and adjusted relationships, respectively. Blue and red dotted lines represent $95 \%$ confidence intervals for unadjusted and adjusted relationships, respectively. In both spline curves, degree of freedom was 16 and smoothing parameter was 0.01 . There were declining trends in the rates of the composite end point associated with increasing body weight, which flattened out at a body weight of approximately $>4.5 \mathrm{~kg}$. $P A$, Pulmonary artery; $I Q R$, interquartile range.

underwent PAB. Table 1 shows the baseline characteristics stratified according to body weight (above vs below median). Surgery was performed at a median age of 125 (IQR, 79-193) days with a median body weight of
4.94 (IQR, 4.00-6.00) kg. Moreover, 51.8\% of cases were girls and $23.6 \%$ had a chromosomal abnormality. Most cases $(74.7 \%)$ were treated with diuretics at the time of operation. 


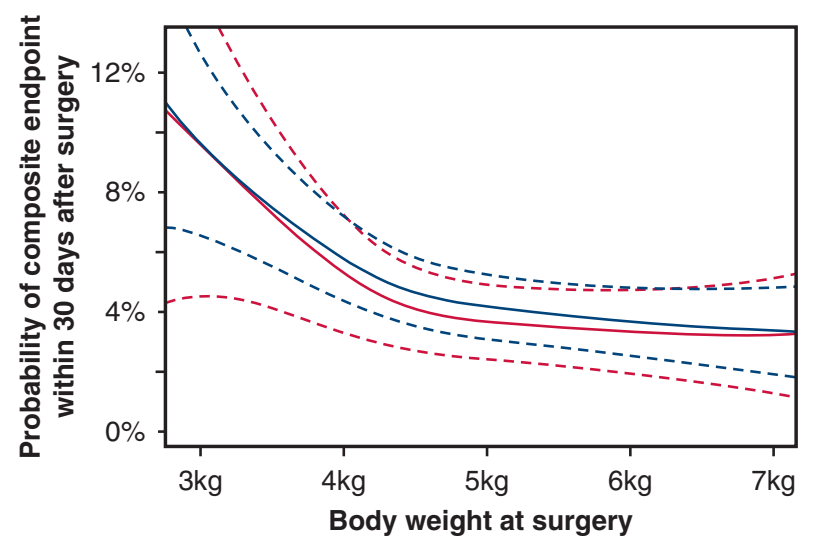

FIGURE 3. Spline relationship between body weight at surgery and composite end point in the ventricular septal defect cohort. Estimated smoothing spline curves to represent the relationship between body weight and the rate of composite end point of all-cause death and major complications within 30 days after surgery in the ventricular septal defect cohort. Solid blue and red lines represent unadjusted and adjusted relationships, respectively. Blue and red dotted lines represent 95\% confidence intervals for unadjusted and adjusted relationships, respectively. In both spline curves, degree of freedom was 16 and smoothing parameter was 0.01 . There were declining trends in the rates of the composite end point associated with increasing body weight, which flattened out at a body weight of approximately $>4.5 \mathrm{~kg}$.

Compared with cases with larger body weight, those with lower body weight were more likely to be girls and have early delivery, along with a chromosomal abnormality and preoperative risk factors. In addition, patients with lower body weight were more likely to be treated with diuretics and intravenous drugs preoperatively and to have $\mathrm{PAB}$ before surgical VSD closure and nonelective operation.

Table 2 shows a summary of clinical outcomes. Overall, $289(5.8 \%)$ patients experienced death or major complication within 30 days after a surgery (outcome of interest), and of these, $23(0.5 \%)$ died. The most common complications were chylothorax $(1.4 \%)$ and unplanned cardiac reoperation $(1.4 \%)$. In our study cohort, pulmonary hypertensive crisis $(0.7 \%)$ and pacemaker implantation $(0.2 \%)$ were uncommon. Compared with patients with larger body weight, those with lower body weight were more likely to experience a composite end point. Especially the rates of death, pulmonary hypertensive crisis, unplanned reoperation, and chylothorax were significantly higher in patients with lower body weight than those with higher body weight.

\section{Relationship Between Outcome and Body Weight at Operation in the Main Cohort}

The rate of composite end point was higher in patients with lower body weight than those with higher body weight $(7.2 \%$ vs $4.5 \% ; P<.001)$. Spline relationships between body weight at operation and composite end point in the main cohort are shown in Figure 2. There were declining trends in the rates of composite end point associated with increasing body weight and flattened out at a body weight of approximately $>4.5 \mathrm{~kg}$. Spline curves with different degrees of freedom and smoothing parameters are presented in Figure E2, which showed consistent findings. After adjusting for baseline differences using the logistic regression models, the risk of composite end point increased with lowering body weight (adjusted OR, 1.56 for every $-1 \mathrm{~kg}$; 95\% CI, 1.30-1.88; $P<.001$; Table 3). Figure E3 shows a contour plot of predicted risk of composite end point according to age and body weight and shows cases with approximately $<4.5 \mathrm{~kg}$ of body weight had higher predicted risk, regardless of age. This is also illustrated in Figure E4, a distribution of predicted risk of composite end point in relation to age and body weight at surgery.

\section{Relationship Between Outcome and Body Weight at Operation in the VSD Cohort}

Among 4947 cases in the main cohort, surgical VSD closure was performed in 4310 cases. After excluding 340 patients with previous $\mathrm{PAB}$, we identified 3970 patients who underwent surgical VSD closure as a 1-staged surgery (VSD cohort in Figure 1). Baseline characteristics stratified according to body weight and details of clinical outcomes in the VSD cohort are shown in Tables E3 and E4, respectively. Spline curves showing relationships between body weight and composite end point are represented in Figure 3, showing that the risk of composite end point was low along with increasing body weight with an inflection point at a body weight of approximately $>4.5 \mathrm{~kg}$. These findings were similar to that from the main analysis. Sensitivity analyses using spline curves with different degrees of freedom and smoothing parameters showed the robustness of our findings (Figure E5). Logistic regression models revealed that lower body weight was significantly associated with a higher rate of composite end point even after accounting for baseline differences (adjusted OR, 1.59 for every $-1 \mathrm{~kg} ; 95 \% \mathrm{CI}$, 1.27-1.99; $P<.001$; Table 3).

\section{Characteristics and Clinical Outcomes in the PAB Cohort}

Baseline characteristics and clinical outcomes within 30 days in the PAB cohort $(n=637)$ are shown in Table 4. PAB was performed at the median age of 45 days (IQR, 27-81) with a median body weight of $2.88 \mathrm{~kg}$ (IQR, 2.20-3.70). A total of 275 (43.2\%) cases were complicated with chromosomal abnormality, of these, $56(8.8 \%)$ had trisomy 18 and $1(0.2 \%)$ had trisomy 13 , whereas most of them had trisomy $21(\mathrm{n}=203 ; 31.9 \%)$. In the PAB cohort, the proportion of multiple, inlet, and muscular types of VSD was higher than in the VSD cohort $(6.4 \%$ vs $0.6 \%$ for 
TABLE 1. Baseline characteristics of the main cohort

\begin{tabular}{|c|c|c|c|c|}
\hline Characteristic & $\begin{array}{c}\text { Overall } \\
(n=4947)\end{array}$ & $\begin{array}{c}\text { Below median BW } \\
(\mathrm{n}=\mathbf{2 4 7 3})\end{array}$ & $\begin{array}{c}\text { Above median BW } \\
\quad(n=2474)\end{array}$ & $\begin{array}{c}P \\
\text { value } \\
\end{array}$ \\
\hline \multicolumn{5}{|l|}{ Demographic } \\
\hline Median BW at operation (25th-75th percentile), $\mathrm{kg}$ & $4.94(4.00-6.00)$ & $4.00(3.30-4.50)$ & $6.00(5.41-6.90)$ & $<.001$ \\
\hline Median age at operation (25th-75th percentile), d & $125(79-193)$ & $82.0(52.0,113)$ & $185(136,249)$ & $<.001$ \\
\hline Age at operation $<28 \mathrm{~d}, \mathrm{n}(\%)$ & $231(4.7)$ & $222(9.0)$ & $9(0.4)$ & $<.001$ \\
\hline Girl, n (\%) & $2563(51.8)$ & $1436(58.1)$ & $1127(45.6)$ & $<.001$ \\
\hline Early delivery, n (\%) & $635(12.8)$ & $430(17.4)$ & $205(8.3)$ & $<.001$ \\
\hline Chromosomal abnormality, $\mathrm{n}(\%)$ & $1169(23.6)$ & $762(30.8)$ & $407(16.5)$ & $<.001$ \\
\hline Any preoperative risk factor, $\mathrm{n}(\%)$ & $374(7.6)$ & $270(10.9)$ & $104(4.2)$ & $<.001$ \\
\hline \multicolumn{5}{|l|}{ VSD morphology, n (\%) } \\
\hline Multiple & $80(1.6)$ & $52(2.1)$ & $28(1.1)$ & \\
\hline Type 1 (infundibular) & $564(11.4)$ & $185(7.5)$ & $379(15.3)$ & \\
\hline Type 2 (membranous) & $3989(80.6)$ & $2079(84.1)$ & $1910(77.2)$ & \\
\hline Type 3 (inlet) & $134(2.7)$ & $79(3.2)$ & $55(2.2)$ & \\
\hline Type 4 (muscular) & $177(3.6)$ & $78(3.2)$ & $99(4.0)$ & \\
\hline Gerbode type & $3(0.1)$ & $0(0)$ & $3(0.1)$ & \\
\hline \multicolumn{5}{|l|}{ Preoperation status, $\mathrm{n}(\%)$} \\
\hline Home oxygen therapy & $82(1.7)$ & 48 (1.9) & $34(1.4)$ & .119 \\
\hline ACE inhibitors & $438(8.9)$ & $184(7.8)$ & $244(9.9)$ & .013 \\
\hline Digitalis & $486(9.8)$ & $267(10.8)$ & $219(8.9)$ & .022 \\
\hline Diuretics & $3696(74.7)$ & $1924(77.8)$ & $1772(71.6)$ & $<.001$ \\
\hline Intravenous drugs & $247(5.0)$ & $221(8.9)$ & $26(1.1)$ & $<.001$ \\
\hline \multicolumn{5}{|l|}{ Operation detail } \\
\hline Median preoperative length of stay (25th-75th percentile), $d$ & $3(2-6)$ & $4(2-12)$ & $3(2-4)$ & $<.001$ \\
\hline VSD closure, n (\%) & $4310(87.1)$ & $1884(76.2)$ & $2426(98.1)$ & $<.001$ \\
\hline PAB, n (\%) & 637 (12.9) & $589(23.8)$ & 48 (1.9) & $<.001$ \\
\hline Initial surgery, n (\%) & $4575(92.5)$ & $2370(95.8)$ & $2205(89.1)$ & $<.001$ \\
\hline Status of surgery, $\mathrm{n}(\%)$ & & & & $<.001$ \\
\hline Elective & $4759(96.2)$ & $2307(93.3)$ & $2452(99.1)$ & \\
\hline Other than elective & $188(3.8)$ & $166(6.7)$ & $22(0.9)$ & \\
\hline Transfusion & $4429(89.5)$ & $2241(90.6)$ & $2188(88.4)$ & .012 \\
\hline
\end{tabular}

$B W$, Body weight; $V S D$, ventricular septal defect; $A C E$, angiotensin-converting enzyme; $P A B$, pulmonary artery banding.

multiple; $4.6 \%$ vs $2.3 \%$ for inlet; $7.4 \%$ vs $2.8 \%$ for muscular). In the PAB cohort, $17.6 \%$ of cases were treated with intravenous drugs preoperatively, and $16.6 \%$ of $\mathrm{PAB}$ were performed in nonelective settings. Among the PAB cohort, the rates of mortality and major complications within 30 days were $1.4 \%(\mathrm{n}=9)$ and $7.7 \%(\mathrm{n}=49)$, respectively.

\section{DISCUSSION}

Three main findings were obtained in this nationwide analysis that assessed the association between body weight at the time of surgery and in-hospital outcome in patients diagnosed with VSD who underwent surgical intervention at younger than 1 year of age. First, surgical interventions were safely performed and most cases $(94.2 \%)$ were uncomplicated. Second, a lower body weight was consistently associated with a higher rate of composite end point including death and/or major complications within 30 days after surgery. The rate of composite end point decreased along with increasing body weight and plateaued at approximately $>4.5 \mathrm{~kg}$, which could be a valid threshold for body weight at surgery with acceptable risks. Importantly, cases with approximately $<4.5 \mathrm{~kg}$ of body weight had greater predicted risk regardless of age, suggesting that body weight might be a more decisive factor for a composite end point. Finally, PAB is still commonly used before surgical VSD closure or for the purpose of palliation in Japan, and its related mortality was $1.4 \%$ (Video 1).

Within the past decade, at least 4 studies reported an association of body weight and clinical outcomes in infants who underwent surgical VSD closure, yet the findings were inconsistent. ${ }^{5-8}$ However, all of these previous studies were performed in a single center and included relatively small sample sizes. Although 2 studies generated multivariable models for identifying factors associated with prolonged hospital stay or prolonged ventilation, ${ }^{7,8}$ none of the studies reported the adjusted association of body weight and clinical outcomes, likely because of a limited number of events. Unlike previous investigations, our analyses 
TABLE 2. Details of clinical outcomes in the main cohort

\begin{tabular}{|c|c|c|c|c|}
\hline Outcome & $\begin{array}{l}\text { Main cohort } \\
(n=4947)\end{array}$ & $\begin{array}{l}\text { Below median BW } \\
\quad(\mathrm{n}=\mathbf{2 4 7 3})\end{array}$ & $\begin{array}{l}\text { Above median BW } \\
\quad(n=2474)\end{array}$ & $\begin{array}{c}P \\
\text { value }\end{array}$ \\
\hline Death or major complication & $289(5.8)$ & $177(7.2)$ & $112(4.5)$ & $<.001$ \\
\hline Death & $23(0.5)$ & $18(0.7)$ & $5(0.2)$ & .007 \\
\hline \multicolumn{5}{|l|}{ Major complications } \\
\hline Cardiac arrest & $24(0.5)$ & $16(0.6)$ & $8(0.3)$ & .101 \\
\hline Circulatory instability requiring mechanical support & $11(0.2)$ & $6(0.2)$ & $5(0.2)$ & .762 \\
\hline Pulmonary hypertensive crisis & $36(0.7)$ & $25(1.0)$ & $11(0.4)$ & .019 \\
\hline Unplanned cardiac reoperation & $68(1.4)$ & $47(1.9)$ & $21(0.8)$ & .001 \\
\hline Unplanned noncardiac reoperation & $32(0.6)$ & $9(0.4)$ & $10(0.4)$ & .819 \\
\hline Unplanned reoperation for bleeding & $19(0.4)$ & $24(1.0)$ & $8(0.3)$ & .005 \\
\hline Arrhythmia requiring PMI & $11(0.2)$ & $3(0.1)$ & $8(0.3)$ & .131 \\
\hline Arrhythmia requiring cardioversion & $15(0.3)$ & $10(0.4)$ & $5(0.2)$ & .196 \\
\hline Chylothorax & $69(1.4)$ & $43(1.7)$ & $26(1.1)$ & .039 \\
\hline Respiratory failure requiring tracheotomy & $11(0.2)$ & $7(0.3)$ & $4(0.2)$ & .365 \\
\hline $\begin{array}{l}\text { Acute renal failure requiring hemodialysis or } \\
\text { hemofiltration persisting at discharge }\end{array}$ & $8(0.2)$ & $3(0.1)$ & $5(0.2)$ & .706 \\
\hline Neurological deficit persisting at discharge & $13(0.3)$ & $4(0.2)$ & $9(0.4)$ & .165 \\
\hline Phrenic nerve paralysis & $14(0.3)$ & $7(0.3)$ & $7(0.3)$ & .999 \\
\hline Mediastinitis & $29(0.6)$ & $14(0.6)$ & $15(0.6)$ & .853 \\
\hline Deep wound infection & $16(0.3)$ & $6(0.2)$ & $10(0.4)$ & .317 \\
\hline Post-operative length of stay, median (25th-75th percentile), $d$ & $14(10,19)$ & $15(11,23)$ & $12(9,16)$ & $<.001$ \\
\hline
\end{tabular}

$B W$, Body weight; $P M I$, pacemaker implantation.

included a large contemporary cohort of patients who underwent surgical intervention (VSD closure and/or PAB) using a nationwide Japanese cohort. We showed that lower body weight was significantly associated with increased risk of the composite end point of death and major complications within 30 days after surgery, even after accounting for baseline differences. This finding shows that, despite the advancement of surgical devices, techniques, and equipment in modern practice, body weight is still a dominant factor in stratifying the risk of surgery even for relatively "low-risk" congenital cardiac abnormality such as VSD.

The threshold value of body weight for performing surgical VSD closure with acceptable perioperative risk is mainly derived from expert experience or consensus and has not been validated. Our analyses showed that the risk of the composite end point decreased along with increasing body weight and plateaued at approximately $>4.5 \mathrm{~kg}$.

TABLE 3. Adjusted association of body weight at surgery and composite endpoint

\begin{tabular}{|c|c|c|c|c|}
\hline & \multicolumn{2}{|c|}{ Main cohort $(n=4947)$} & \multicolumn{2}{|c|}{ VSD cohort $(n=3970)$} \\
\hline & $\overline{\text { Adjusted OR (95\% CI) }}$ & $P$ value & $\overline{\text { Adjusted OR (95\% CI) }}$ & $P$ value \\
\hline Lower body weight, per $-1 \mathrm{~kg}$ & $1.56(1.30-1.88)$ & $<.001$ & $1.59(1.27-1.99)$ & $<.001$ \\
\hline Girl & $0.90(0.70-1.15)$ & .392 & $1.02(0.78-1.33)$ & .909 \\
\hline Age at operation $<28 \mathrm{~d}$ & $0.67(0.37-1.21)$ & .189 & $0.52(0.15-1.81)$ & .306 \\
\hline Early delivery & $1.06(0.77-1.47)$ & .707 & $1.14(0.78-1.66)$ & .504 \\
\hline History of previous cardiac surgery & $2.85(2.00-4.05)$ & $<.001$ & $2.99(2.06-4.33)$ & $<.001$ \\
\hline Home oxygen therapy & $0.73(0.34-1.58)$ & .424 & $0.66(0.27-1.64)$ & .375 \\
\hline Intravenous drugs & $1.05(0.64-1.71)$ & .845 & $1.30(0.70-2.42)$ & .405 \\
\hline Any preoperative risk factors & $1.69(1.16-2.44)$ & .006 & $2.32(1.53-3.51)$ & $<.001$ \\
\hline Preoperative use of ACE inhibitors & $1.25(0.81-1.92)$ & .317 & $1.28(0.82-2.00)$ & .275 \\
\hline Preoperative use of digitalis & $0.53(0.32-0.90)$ & .019 & $0.49(0.27-0.89)$ & .019 \\
\hline Preoperative use of diuretics & $1.04(0.78-1.39)$ & .766 & $1.03(0.75-1.43)$ & .847 \\
\hline Status of surgery (other than elective) & $1.32(0.77-2.26)$ & .321 & $0.92(0.37-2.28)$ & .852 \\
\hline Chromosomal abnormality & $1.97(1.52-2.56)$ & $<.001$ & $2.16(1.62-2.88)$ & $<.001$ \\
\hline Transfusion & $1.49(0.94-2.36)$ & .089 & $1.35(0.71-2.53)$ & .359 \\
\hline
\end{tabular}

$V S D$, Ventricular septal defect; $O R$, odds ratio; $C I$, confidence interval; $A C E$, angiotensin-converting enzyme. 
TABLE 4. Details of characteristics and clinical outcomes in the PAB cohort $(n=637)$

\begin{tabular}{|c|c|}
\hline Characteristic & Value \\
\hline \multicolumn{2}{|l|}{ Demographic } \\
\hline $\begin{array}{l}\text { Median body weight at operation } \\
\text { (25th-75th percentile), } \mathrm{kg}\end{array}$ & $2.88(2.20-3.70)$ \\
\hline Median age at operation ( 25 th- 75 th percentile), d & $45(27-81)$ \\
\hline Age at operation $<28 \mathrm{~d}, \mathrm{n}(\%)$ & $164(25.7)$ \\
\hline Girl, n (\%) & $361(56.7)$ \\
\hline Early delivery, $\mathrm{n}(\%)$ & $191(30.0)$ \\
\hline Chromosomal abnormality, n (\%) & $275(43.2)$ \\
\hline Trisomy 21 & $203(31.9)$ \\
\hline Trisomy 18 & $56(8.8)$ \\
\hline Trisomy 13 & $1(0.2)$ \\
\hline Other chromosomal abnormality & $15(2.4)$ \\
\hline Any preoperative risk factor, $\mathrm{n}(\%)$ & $133(20.9)$ \\
\hline \multicolumn{2}{|l|}{ VSD morphology, n (\%) } \\
\hline Multiple & $41(6.4)$ \\
\hline Type 1 (infundibular) & $24(3.8)$ \\
\hline Type 2 (membranous) & $496(77.9)$ \\
\hline Type 3 (inlet) & $29(4.6)$ \\
\hline Type 4 (muscular) & $47(7.4)$ \\
\hline Gerbode type & $0(0)$ \\
\hline \multicolumn{2}{|l|}{ Preoperation status } \\
\hline Home oxygen therapy, n (\%) & $25(3.9)$ \\
\hline ACE inhibitors, $\mathrm{n}(\%)$ & $20(3.1)$ \\
\hline Digitalis, $\mathrm{n}(\%)$ & $63(9.9)$ \\
\hline Diuretics, $\mathrm{n}(\%)$ & $451(70.8)$ \\
\hline Intravenous drugs, $\mathrm{n}(\%)$ & $112(17.6)$ \\
\hline \multicolumn{2}{|l|}{ Operation detail } \\
\hline $\begin{array}{l}\text { Median preoperative length of stay } \\
\text { (25th-75th percentile), } d\end{array}$ & $8(3-21)$ \\
\hline \multicolumn{2}{|l|}{ Status of surgery } \\
\hline Elective, n $(\%)$ & $531(83.4)$ \\
\hline Other than elective, $\mathrm{n}(\%)$ & $106(16.6)$ \\
\hline Transfusion, $\mathrm{n}(\%)$ & $452(71.0)$ \\
\hline \multicolumn{2}{|l|}{ Outcome within $30 \mathrm{~d}$ after PAB } \\
\hline Death or major complications & $54(8.5)$ \\
\hline Death & $9(1.4)$ \\
\hline Major complications & $49(7.7)$ \\
\hline
\end{tabular}

Aydemir and colleagues reported the characteristics and results of patients who underwent surgical closure for isolated VSD at younger than 1 year of age, which was a similar inclusion factor for our study population, and reported that the median body weight at surgery was $5.3 \mathrm{~kg},{ }^{4}$ suggesting that approximately $>4.5 \mathrm{~kg}$ would be a reasonable cutoff value in current practice outside Japan. Moreover, our proposed threshold might also be applicable to surgery for other congenital heart diseases that are classified into the same Risk Adjusted Classification for Congenital Heart Surgery (RACHS-1) category (category 2) as VSD, because of its validated categorization on the basis of estimated risk. ${ }^{13}$
In current practice, $\mathrm{PAB}$ is rarely considered for VSD, except in patients with either many VSDs or apical malformations, in whom surgical access to anomalies is anticipated to be difficult or impossible. ${ }^{9}$ Therefore, limited data are available regarding indications and results of PABs that were performed in patients with primary diagnosis of VSD in contemporary practice. Takayama and colleagues summarized the results of PAB performed between 1966 and 2001 in a single Japanese center ${ }^{14}$ and reported that the number of PABs that were performed for VSD was decreasing over time. However, in our study cohort, $7.9 \%$ of patients (340 of 4310 cases) who underwent surgical VSD closure had a previous PAB, suggesting PAB is still a common practice to manage patients with VSD in Japan. In our PAB cohort, the median body weight at the time of PAB was 2.88 (IQR, 2.20-3.70) kg, which was lower than the value reported by Takayama and colleagues and shows that $\mathrm{PAB}$ is now performed in patients with lower body weight. The mortality after PAB in our study cohort was $1.4 \%$, which was much lower than that in previous reports, likely because of the advancement in surgical devices and techniques and differences in background disease and/or follow-up period among studies. ${ }^{14,15}$ Despite the low mortality rate after $\mathrm{PAB}$ in contemporary practice, physicians should be aware of the risks of mortality and/ or major complications related to $\mathrm{PAB}$ and cautiously consider its indications, because of the recent satisfactory results after 1-stage operations and lower threshold of body weight with an acceptable perioperative risk.

In our PAB cohort, $43.2 \%$ of cases were complicated with chromosomal abnormality, and of these, $20.7 \%$ (57 of 275 cases) had trisomy 18 or trisomy 13 . These trisomies are known to be associated with multiple extracardiac defects, severe growth failure, developmental delay, and poor prognosis, resulting in death within 1 year after birth. ${ }^{16,17}$ In our study, infants with extracardiac defects were excluded from the analysis, but the chromosomal abnormalities should have affected their outcomes. Because most deaths are related to noncardiac causes, such as central apnea, respiratory and/or feeding problems related to marked developmental delay, intracardiac repair is rarely performed. Maeda and colleagues published a nationwide survey on cardiac surgery in patients with trisomy 18 or trisomy 13 , and reported that most cardiac surgery for this population was performed for a palliative purpose. ${ }^{18}$ Our study confirmed this previous report and showed that PAB was also widely performed in patients with chromosomal abnormality, likely with the aim of palliation.

\section{Limitation}

Our findings should be interpreted in the context of potential limitations. First, despite our use of available variables to adjust for potential confounding, residual 


\section{Ventricular Septal Defect}

- Most common form of congenital cardiac abnormality

- About $50 \%$ of infants and children require surgical closure

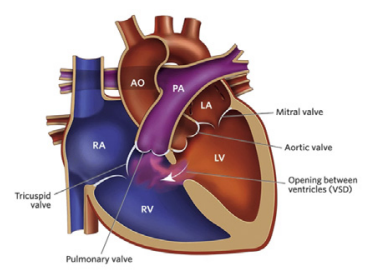

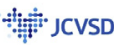

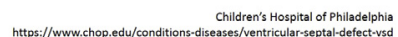

VIDEO 1. The importance and relevance of the report. Video available at: https://www.jtcvs.org/article/S0022-5223(18)33264-1/fulltext.

and/or unmeasured confounding might exist. However, to the best of our knowledge, our analysis is the first study that includes the adjusted association of body weight at surgery and clinical outcomes in patients diagnosed with VSD. Second, in our main cohort, patients who underwent $\mathrm{PAB}$ and subsequent surgical VSD closure were considered as 2 cases, because the registration to the JCVSD is on the basis of operation, which might skew the results. However, sensitivity analyses using the VSD cohort showed consistent results, which supported the scientific robustness of our findings. Furthermore, one of the critical limitations of the previous literature was that they did not consider patients who underwent $\mathrm{PAB}$ but did not undergo subsequent VSD closure, when the association of body weight and clinical outcomes was evaluated. Because of the potential risks of mortality and complications after $\mathrm{PAB}$, it is critically important to consider this specific population. Our approach enabled us to account for these potential risks and overcome the limitation of previous studies. Third, generalizability of the results is an issue. Although the JCVSD is a nationwide registry and our study cohort is a representative cohort of Japanese patients, our findings might not be fully applicable to the clinical practice outside Japan, because practice patterns could vary among countries. Finally, long-term outcomes were not available in our data set. Recently, reports from the Dutch National Population Registry showed that the prognosis of successful surgical VSD closure was slightly worse than that in the general population after long-term follow-up. ${ }^{19,20}$ Therefore, further studies are necessary to investigate whether body weight at surgery is associated with long-term clinical outcomes.

\section{CONCLUSIONS}

In our study cohort from a nationwide Japanese surgical database, surgical closure or PAB was safely performed for patients diagnosed with VSD at younger than 1 year of age.
Despite the advancements in surgical devices and techniques, lower body weight was significantly associated with increased risks of the composite end point within 30 days after surgery. The risks of the composite end point plateaued at approximately $>4.5 \mathrm{~kg}$ of body weight, which could be a valid threshold with acceptable risk. These findings are useful for patient counseling and might aid in facilitating understanding of the risk of surgery.

\section{Conflict of Interest Statement}

Dr Inohara: research grant from JSPS Overseas Research fellowship and Boston Scientific. Dr Ichihara: Affiliated with the Department of Healthcare Quality Assessment at the University of Tokyo, which is a social collaboration department supported by National Clinical Database, Johnson \& Johnson K.K., and Nipro Corporation. Dr Kohsaka: affiliated with Department of Healthcare Quality Assessment at the University of Tokyo, which is a social collaboration department supported by National Clinical Database, Johnson \& Johnson K.K., and Nipro Corporation, research grants from Bayer Yakuhin Ltd and Daiichi Sankyo Co Ltd, and lecture fees from Bristol Meier Squibb and Bayer Yakuhin Ltd. Dr Miyata: affiliated with Department of Healthcare Quality Assessment at the University of Tokyo, which is a social collaboration department supported by National Clinical Database, Johnson \& Johnson K.K., and Nipro Corporation. All other authors have nothing to disclose with regard to commercial support.

The authors thank the care providers who contributed to the clinical care of these patients. The initial concept of this study was provided through the support of Sota Inohara and Hiromi Kohsaka.

\section{References}

1. van der Linde D, Konings EE, Slager MA, Witsenburg M, Helbing WA, Takkenberg JJ, et al. Birth prevalence of congenital heart disease worldwide: a systematic review and meta-analysis. J Am Coll Cardiol. 2011; $58: 2241-7$.

2. Turner SW, Hornung T, Hunter S. Closure of ventricular septal defects: a study of factors influencing spontaneous and surgical closure. Cardiol Young. 2002;12: 357-63.

3. Eroglu AG, Oztunc F, Saltik L, Bakari S, Dedeoglu S, Ahunbay G. Evolution of ventricular septal defect with special reference to spontaneous closure rate, subaortic ridge and aortic valve prolapse. Pediatr Cardiol. 2003;24:31-5.

4. Aydemir NA, Harmandar B, Karaci AR, Sasmazel A, Bolukcu A, Saritas T, et al. Results for surgical closure of isolated ventricular septal defects in patients under one year of age. J Card Surg. 2013;28:174-9.

5. Kogon B, Butler H, Kirshbom P, Kanter K, McConnell M. Closure of symptomatic ventricular septal defects: how early is too early? Pediatr Cardiol. 2008;29:36-9.

6. Siehr SL, Hanley FL, Reddy VM, Miyake CY, Dubin AM. Incidence and risk factors of complete atrioventricular block after operative ventricular septal defect repair. Congenit Heart Dis. 2014;9:211-5.

7. Anderson BR, Stevens KN, Nicolson SC, Gruber SB, Spray TL, Wernovsky G, et al. Contemporary outcomes of surgical ventricular septal defect closure. J Thorac Cardiovasc Surg. 2013;145:641-7.

8. Schipper M, Slieker MG, Schoof PH, Breur JM. Surgical repair of ventricular septal defect; contemporary results and risk factors for a complicated course. Pediatr Cardiol. 2017;38:264-70.

9. Penny DJ, Vick GW III. Ventricular septal defect. Lancet. 2011;377:1103-12. 
10. Miyata H, Murakami A, Tomotaki A, Takaoka T, Konuma T, Matsumura G, et al. Predictors of 90-day mortality after congenital heart surgery: the first report of risk models from a Japanese database. J Thorac Cardiovasc Surg. 2014;148: 2201-6.

11. Hoashi T, Miyata H, Murakami A, Hirata Y, Hirose K, Matsumura G, et al. The current trends of mortality following congenital heart surgery: the Japan Congenital Cardiovascular Surgery Database. Interact Cardiovasc Thorac Surg. 2015;21:151-6.

12. Tomotaki A, Miyata H, Hashimoto H, Murakami A, Ono M. Results of data verification of the Japan congenital cardiovascular database, 2008 to 2009. World J Pediatr Congenit Heart Surg. 2014;5:47-53.

13. Jenkins KJ, Gauvreau K, Newburger JW, Spray TL, Moller JH, Iezzoni LI. Consensus-based method for risk adjustment for surgery for congenital heart disease. J Thorac Cardiovasc Surg. 2002;123:110-8.

14. Takayama H, Sekiguchi A, Chikada M, Noma M, Ishizawa A, Takamoto S. Mortality of pulmonary artery banding in the current era: recent mortality of PA banding. Ann Thorac Surge. 2002;74:1219-23; discussion: 1223-4.

15. ECSHA. Congenital database. Available at: https://www.echsacongenitaldb.org. Accessed June 20, 2018.
16. Embleton ND, Wyllie JP, Wright MJ, Burn J, Hunter S. Natural history of trisomy 18. Arch Dis Child Fetal Neonatal Ed. 1996;75:F38-41.

17. Wyllie JP, Wright MJ, Burn J, Hunter S. Natural history of trisomy 13. Arch Dis Child. 1994;71:343-5.

18. Maeda J, Yamagishi H, Furutani Y, Kamisago M, Waragai T, Oana S, et al. The impact of cardiac surgery in patients with trisomy 18 and trisomy 13 in Japan. Am J Med Genet A. 2011;155A:2641-6.

19. Roos-Hesselink JW, Meijboom FJ, Spitaels SE, Van Domburg R, Van Rijen EH, Utens EM, et al. Outcome of patients after surgical closure of ventricular septa defect at young age: longitudinal follow-up of 22-34 years. Eur Heart J. 2004;25: 1057-62.

20. Menting ME, Cuypers JA, Opic P, Utens EM, Witsenburg M, van den Bosch AE, et al. The unnatural history of the ventricular septal defect: outcome up to 40 years after surgical closure. J Am Coll Cardiol. 2015; 65:1941-51.

Key Words: ventricular septal defect, surgical closure, pulmonary artery banding, body weight, risk factor 


\section{APPENDIX E1. DETAILS OF PREOPERATIVE RISK FACTORS}

- Cardiopulmonary resuscitation

- Preoperative complete atrioventricular block

- Preoperative/preprocedural mechanical circulatory support (intra-aortic balloon pumping, ventricular assist device, extracorporeal membrane oxygenation, or cardiopulmonary support)

- Shock, persistent at time of surgery

- Shock, resolved at time of surgery

- Diabetes mellitus, insulin-dependent

- Diabetes mellitus, non-insulin-dependent

- Hypothyroidism

- Currently taking steroids as treatment for adrenal insufficiency

- Currently taking steroids for any reason other than treatment of adrenal insufficiency

- Colostomy present

- Enterostomy of small intestine present

- Esophagostomy present

- Gastrostomy present

- Hepatic dysfunction
- Necrotizing enterocolitis, treated medically

- Necrotizing enterocolitis, treated surgically

- Coagulation disorder, hypercoagulable state

- Coagulation disorder, hypocoagulable state not secondary to medication (intrinsic hypocoagulable state)

- Coagulation disorder, hypocoagulable state secondary to medication

- Endocarditis

- Sepsis

- Sepsis with positive blood culture

- Preoperative neurological deficit

- Seizure during lifetime

- Seizure within 48 hours before surgery

- Stroke, cerebrovascular accident, or intracranial hemorrhage $>$ grade 2 during lifetime

- Stroke, cerebrovascular accident, or intracranial hemorrhage $>$ grade 2 within 48 hours before surgery

- Renal dysfunction

- Renal failure requiring dialysis

- Mechanical ventilation to treat cardiorespiratory failure

- Respiratory syncytial virus

- Single lung

- Tracheostomy present

- Other preoperative factors 


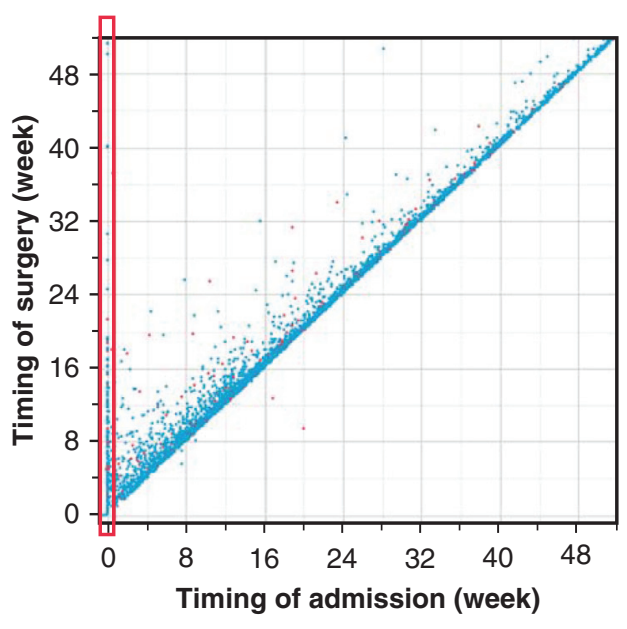

- Death case - Survival case

FIGURE E1. Scatter plot showing the relationship between the timing of admission and the timing of surgery. In this figure, "patients who were admitted as newborns (age of 0 weeks) and remained in the hospital until the time of surgery" corresponds to plots highlighted in the red box. The number of these cases are 204, which is close to the number of patients who underwent surgery at the age of $<28$ days $(n=231)$.
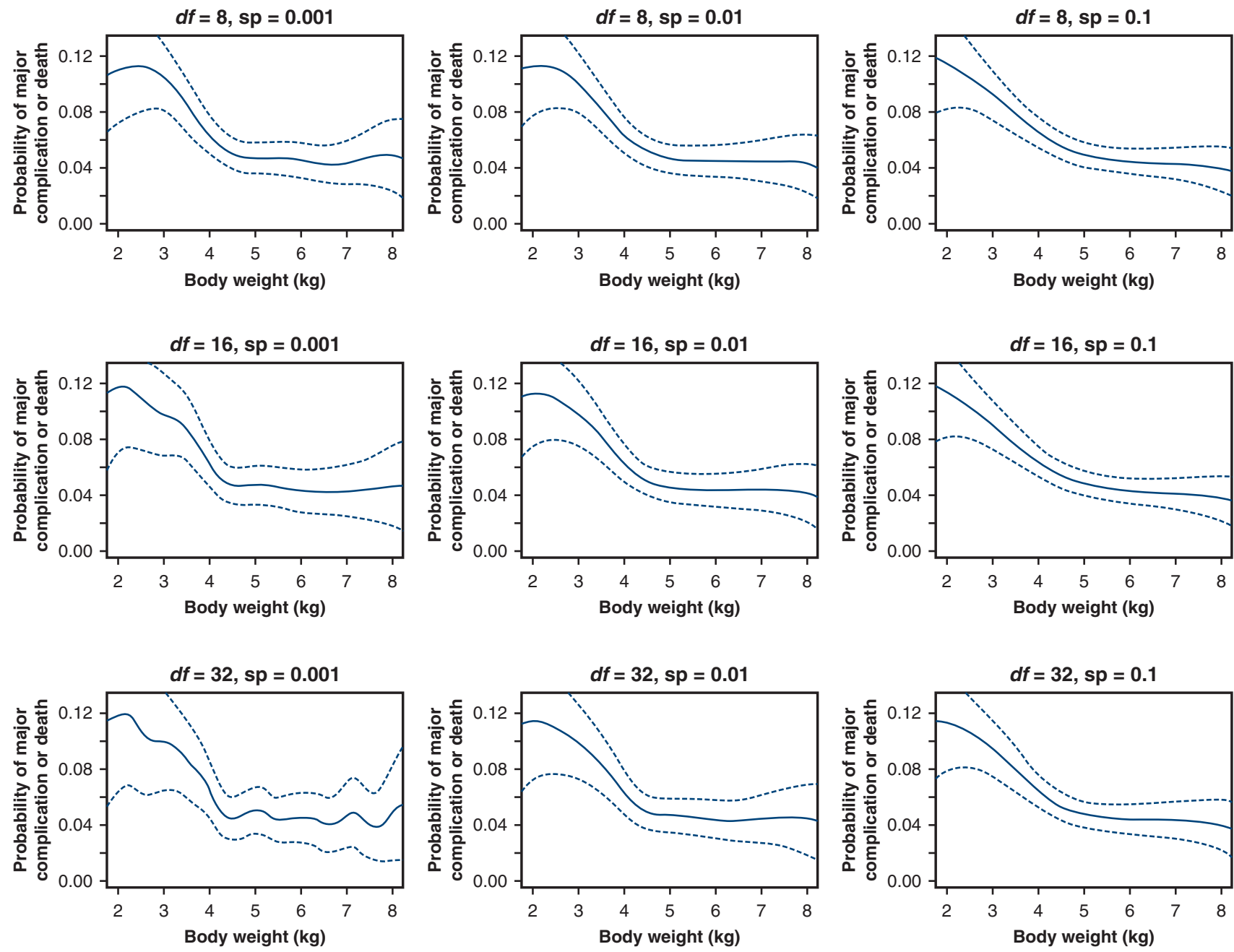

FIGURE E2. Spline curves with different degrees of freedom $(d f)$ and smoothing parameters $(s p)$ in the main cohort. 


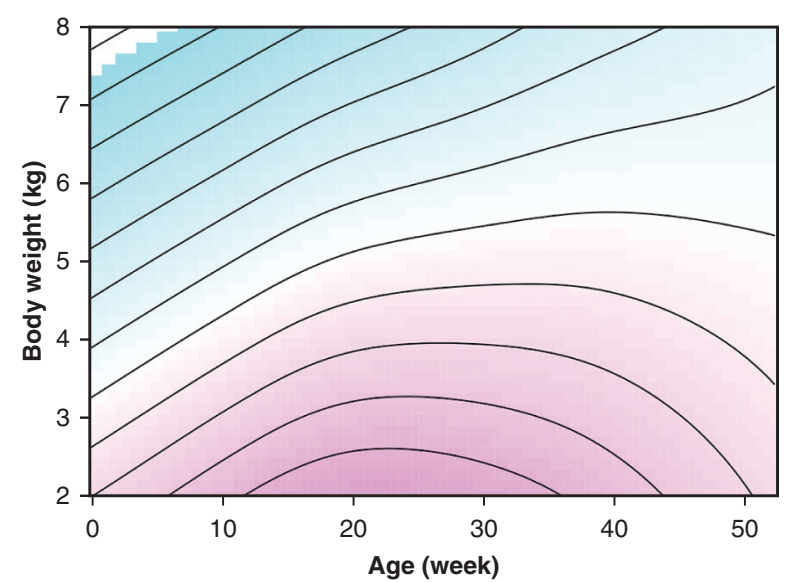

FIGURE E3. Contour plot showing predicted risk of adverse event according to age and body weight. Light blue color indicates lower predicted risk of adverse event, whereas pink color indicates higher predicted risk.

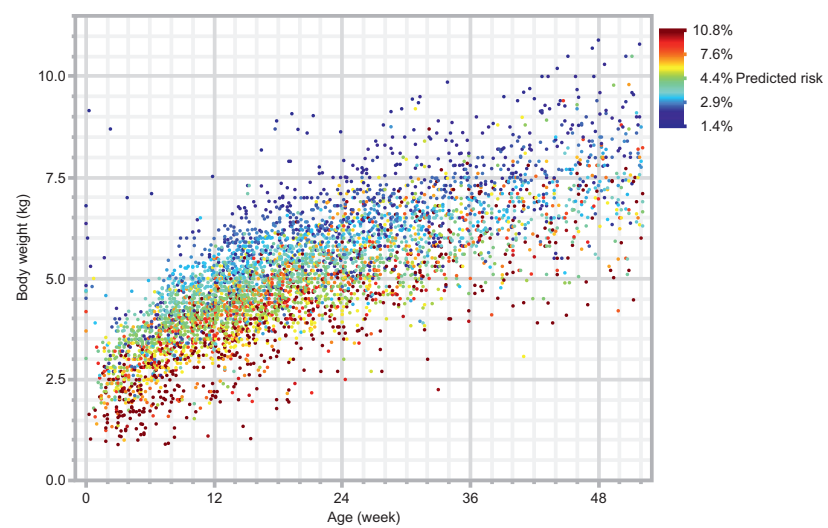

FIGURE E4. Scatter plot showing a distribution of predicted risk of composite end point according to body weight and age at surgery. Predicted risk of composite end point within 30 days after surgery, composite of death and major complications, is represented by different colors in a scatterplot to illustrate its relation to age and body weight at surgery. The risk of composite end point was calculated using a model incorporating age, body weight, and other clinical variables listed in the Methods section. 

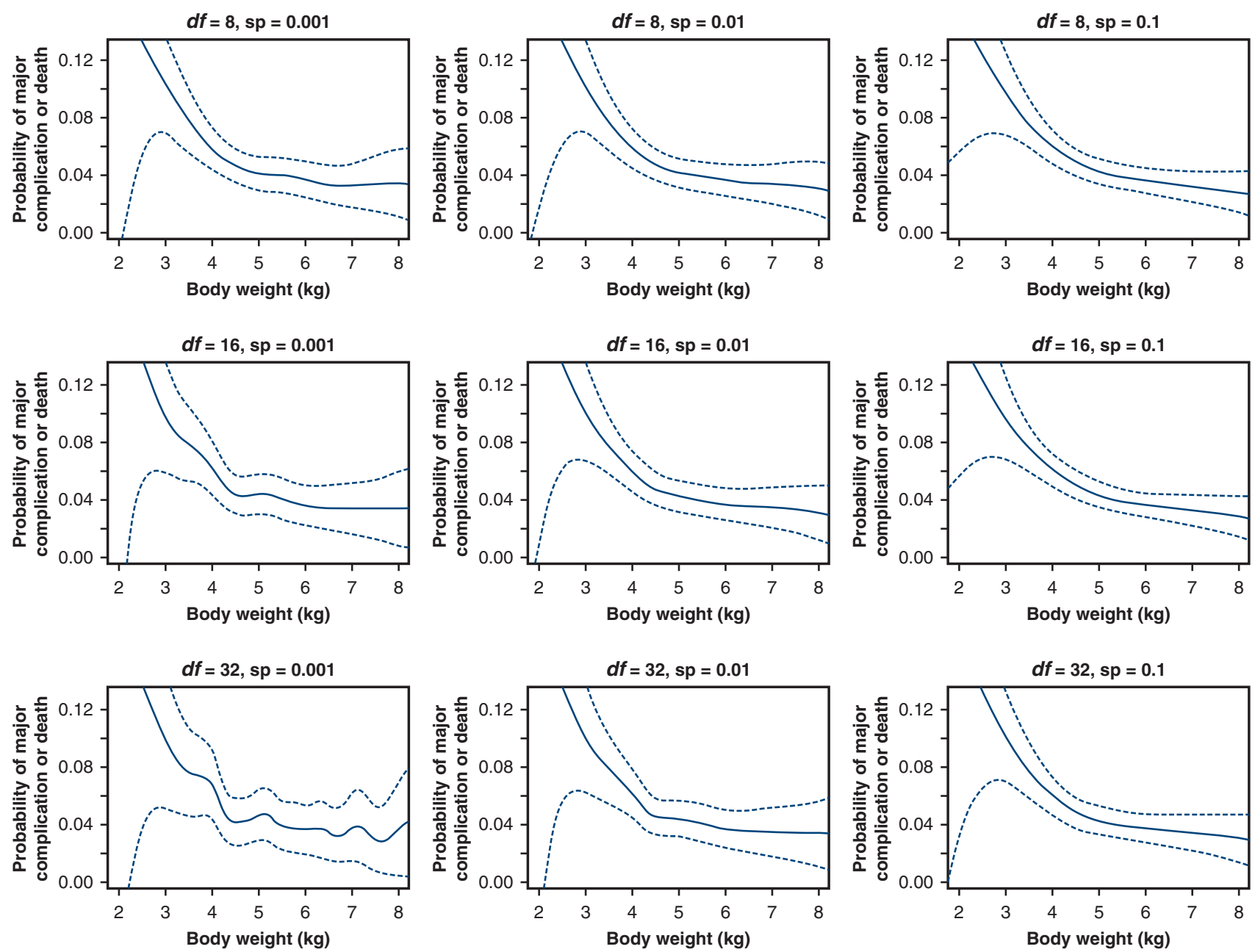

FIGURE E5. Spline curves with different degrees of freedom $(d f)$ and smoothing parameter $(s p)$ in the ventricular septal defect cohort. 
TABLE E1. Concomitant diagnoses

\begin{tabular}{|c|c|}
\hline Diagnosis & Cases, n (\%) \\
\hline Patent ductus arteriosus & $50(5.0)$ \\
\hline Patent foramen ovale & $32(3.2)$ \\
\hline Status post pulmonary artery banding & $18(1.8)$ \\
\hline Atrial septal defect, secundum & $16(1.6)$ \\
\hline Status post patent ductus arteriosus closure, surgical & $12(1.2)$ \\
\hline Pulmonary stenosis, valvar & $8(0.8)$ \\
\hline Tricuspid regurgitation, non-Ebstein related & $8(0.8)$ \\
\hline Primary pulmonary hypertension & $7(0.7)$ \\
\hline Pulmonary stenosis, subvalvular & $5(0.5)$ \\
\hline Mitral regurgitation & $3(0.3)$ \\
\hline Systemic venous anomaly & $3(0.3)$ \\
\hline Vascular ring & $3(0.3)$ \\
\hline Airway disease & $2(0.2)$ \\
\hline Coronary artery anomaly, fistula & $2(0.2)$ \\
\hline Miscellaneous, other & $2(0.2)$ \\
\hline Pulmonary artery stenosis (hypoplasia), main (trunk) & $2(0.2)$ \\
\hline $\begin{array}{l}\text { Pulmonary artery stenosis, branch, central } \\
\text { (within the hilar bifurcation) }\end{array}$ & $2(0.2)$ \\
\hline Tracheal stenosis & $2(0.2)$ \\
\hline Aortic arch hypoplasia & $1(0.1)$ \\
\hline Aortic valve, other & $1(0.1)$ \\
\hline Atrioventricular septal defect & $1(0.1)$ \\
\hline Cardiac, other & $1(0.1)$ \\
\hline $\begin{array}{l}\text { Cardiomyopathy (including dilated, } \\
\text { restrictive, and hypertrophic) }\end{array}$ & $1(0.1)$ \\
\hline Double outlet right ventricle, VSD type & $1(0.1)$ \\
\hline Endocarditis & $1(0.1)$ \\
\hline Hypoplastic left heart syndrome & $1(0.1)$ \\
\hline Hypoplastic left ventricle & $1(0.1)$ \\
\hline Hypoplastic right ventricle & $1(0.1)$ \\
\hline Mitral stenosis, subvalvular & $1(0.1)$ \\
\hline Peripheral vascular, other & $1(0.1)$ \\
\hline $\begin{array}{l}\text { Pulmonary artery stenosis, branch, peripheral } \\
\text { (at or beyond the hilar bifurcation) }\end{array}$ & $1(0.1)$ \\
\hline Pulmonary valve, other & $1(0.1)$ \\
\hline Tetralogy of Fallot, pulmonary stenosis & $1(0.1)$ \\
\hline Truncal valve insufficiency & $1(0.1)$ \\
\hline
\end{tabular}

Cases that were performed in $2012(\mathrm{n}=991)$ are summarized. VSD, Ventricular septal defect.
TABLE E2. Concomitant procedures

\begin{tabular}{lc}
\hline \multicolumn{1}{c}{ Procedure } & Procedures, n (\%) \\
\hline PFO, primary closure & $250(25.2)$ \\
\hline PDA closure, surgical & $165(16.6)$ \\
\hline ASD repair, primary closure & $144(14.5)$ \\
\hline PA banding & $107(10.8)$ \\
\hline Valvuloplasty, tricuspid & $41(4.1)$ \\
\hline PA debanding & $32(3.2)$ \\
\hline RVOT procedure & $25(2.5)$ \\
\hline PA, reconstruction & $22(2.2)$ \\
\hline Valvuloplasty, pulmonic & $9(0.9)$ \\
\hline DCRV repair & $8(0.8)$ \\
\hline Valve surgery, other, tricuspid & $8(0.8)$ \\
\hline Other procedure & $6(0.6)$ \\
\hline Valve surgery, other, pulmonic & $5(0.5)$ \\
\hline Vascular ring repair & $5(0.5)$ \\
\hline Valve surgery, other, mitral & $5(0.5)$ \\
\hline Valvuloplasty, mitral & $5(0.5)$ \\
\hline Coronary artery fistula ligation & $5(0.5)$ \\
\hline Pulmonary venous stenosis repair & $5(0.5)$ \\
\hline Aortic stenosis, subvalvular, repair & $5(0.5)$ \\
\hline Cardiac procedure, other & $5(0.5)$ \\
\hline Ligation, pulmonary artery & $5(0.5)$ \\
\hline PAPVC repair & $5(0.5)$ \\
\hline Valve excision, tricuspid (without replacement) & $5(0.5)$ \\
\hline Valvuloplasty, truncal valve & $5(0.5)$ \\
\hline Case & \\
\hline
\end{tabular}

Cases that were performed in $2012(\mathrm{n}=991)$ are summarized. $P F O$, Patent foramen ovale; $P D A$, patent ductus arteriosus; $A S D$, atrial septal defect; $P A$, pulmonary artery; $R V O T$, right ventricular outflow tract; $D C R V$, double-chambered right ventricle; $P A P V C$, partial anomalous pulmonary venous connection. 
TABLE E3. Baseline characteristics of the VSD cohort

\begin{tabular}{|c|c|c|c|c|}
\hline Characteristic & $\begin{array}{c}\text { Overall } \\
(\mathbf{n}=3970)\end{array}$ & $\begin{array}{c}\text { Below median BW } \\
\quad(\mathbf{n}=\mathbf{1 8 0 6})\end{array}$ & $\begin{array}{l}\text { Above median BW } \\
\quad(n=2164)\end{array}$ & $\begin{array}{c}P \\
\text { value }\end{array}$ \\
\hline \multicolumn{5}{|l|}{ Demographic } \\
\hline Median BW at operation (25th-75th percentile), $\mathrm{kg}$ & $5.08(4.27-6.10)$ & $4.20(3.71-4.58)$ & $6.00(5.40-6.80)$ & $<.001$ \\
\hline Median age at operation (25th-75th percentile), d & $129(89-192)$ & $91.0(64.0-119)$ & $179(132-240)$ & $<.001$ \\
\hline Age at operation $<28 \mathrm{~d}, \mathrm{n}(\%)$ & $66(1.7)$ & $58(3.2)$ & $8(0.4)$ & $<.001$ \\
\hline Girl, n $(\%)$ & $2563(51.8)$ & $1063(58.9)$ & $961(44.4)$ & $<.001$ \\
\hline Early delivery, $\mathrm{n}(\%)$ & $353(8.9)$ & $213(11.8)$ & $140(6.5)$ & $<.001$ \\
\hline Chromosomal abnormality, $\mathrm{n}(\%)$ & $764(19.2)$ & $481(26.6)$ & $283(13.1)$ & $<.001$ \\
\hline Any preoperative risk factor, $\mathrm{n}(\%)$ & $206(5.2)$ & $134(7.4)$ & $72(3.3)$ & $<.001$ \\
\hline \multicolumn{5}{|l|}{ VSD morphology, n (\%) } \\
\hline Multiple & $24(0.6)$ & $13(0.7)$ & $11(0.5)$ & \\
\hline Type 1 (infundibular) & $521(13.1)$ & $155(8.6)$ & $366(16.9)$ & \\
\hline Type 2 (membranous) & $3220(81.1)$ & $1550(85.8)$ & $1670(77.2)$ & \\
\hline Type 3 (inlet) & $93(2.3)$ & $51(2.8)$ & $42(1.9)$ & \\
\hline Type 4 (muscular) & $109(2.8)$ & $37(2.1)$ & $72(3.3)$ & \\
\hline Gerbode type & $3(0.1)$ & $0(0)$ & $3(0.1)$ & \\
\hline \multicolumn{5}{|l|}{ Preoperation status, $\mathrm{n}(\%)$} \\
\hline Home oxygen therapy & $27(0.7)$ & $17(0.9)$ & $10(0.5)$ & .067 \\
\hline ACE inhibitors & $395(9.9)$ & $171(9.5)$ & $224(10.4)$ & .355 \\
\hline Digitalis & $408(10.3)$ & $206(11.4)$ & $202(9.3)$ & .032 \\
\hline Diuretics & $3022(76.1)$ & $1440(79.7)$ & $1582(73.1)$ & $<.001$ \\
\hline Intravenous drugs & $126(3.2)$ & $106(5.9)$ & $20(0.9)$ & $<.001$ \\
\hline \multicolumn{5}{|l|}{ Operation detail } \\
\hline Median preoperative length of stay (25th-75th percentile), d & $3(2-5)$ & $4(3-8)$ & $3(2-4)$ & $<.001$ \\
\hline Status of surgery, $\mathrm{n}(\%)$ & & & & $<.001$ \\
\hline Elective & $3890(98.0)$ & $1743(96.5)$ & $2147(99.2)$ & \\
\hline Other than elective, $\mathrm{n}(\%)$ & $80(2.0)$ & $63(3.5)$ & $17(0.8)$ & \\
\hline Transfusion, $\mathrm{n}(\%)$ & $3648(91.9)$ & $1742(96.5)$ & $1906(88.1)$ & $<.001$ \\
\hline Median cardiopulmonary bypass time ( 25 th- 75 th percentile), minutes & $99(77-124)$ & $98(77-123)$ & $99(76-125)$ & .102 \\
\hline Median cross-clamp time (25th-75th percentile), minutes & $56(43-74)$ & $56(43-73)$ & $57(42-101)$ & .013 \\
\hline
\end{tabular}

$B W$, Body weight; $A C E$, angiotensin-converting enzyme; $V S D$, ventricular septal defect. 
TABLE E4. Details of clinical outcomes in the VSD cohort

\begin{tabular}{|c|c|c|c|c|}
\hline & $\begin{array}{l}\text { VSD cohort } \\
(n=3970)\end{array}$ & $\begin{array}{l}\text { Below median BW } \\
\quad(n=1806)\end{array}$ & $\begin{array}{l}\text { Above median BW } \\
\quad(n=2164)\end{array}$ & $\begin{array}{c}P \\
\text { value }\end{array}$ \\
\hline Death or major complication & $188(4.7)$ & $108(6.0)$ & $80(3.7)$ & $<.001$ \\
\hline Death & $9(0.2)$ & $8(0.4)$ & $1(0.0)$ & .009 \\
\hline \multicolumn{5}{|l|}{ Major complications } \\
\hline Cardiac arrest & $18(0.5)$ & $12(0.7)$ & $6(0.3)$ & .071 \\
\hline Circulatory instability requiring mechanical support & $8(0.2)$ & $5(0.3)$ & $3(0.1)$ & .334 \\
\hline Pulmonary hypertensive crisis & $27(0.7)$ & $17(0.9)$ & $10(0.5)$ & .067 \\
\hline Unplanned cardiac reoperation & $42(1.1)$ & $25(1.4)$ & $17(0.8)$ & .066 \\
\hline Unplanned noncardiac reoperation & $18(0.5)$ & $9(0.5)$ & $8(0.4)$ & .536 \\
\hline Unplanned reoperation for bleeding & $17(0.4)$ & $14(0.8)$ & $4(0.2)$ & .006 \\
\hline Arrhythmia requiring PMI & $6(0.2)$ & $2(0.1)$ & $4(0.2)$ & .55 \\
\hline Arrhythmia requiring cardioversion & $12(0.3)$ & $8(0.4)$ & $4(0.2)$ & .14 \\
\hline Chylothorax & $46(1.2)$ & $27(1.5)$ & $19(0.9)$ & .07 \\
\hline Respiratory failure requiring tracheotomy & $4(0.1)$ & $3(0.2)$ & $1(0.0)$ & .236 \\
\hline Acute renal failure requiring hemodialysis or hemofiltration persisting at discharge & $5(0.1)$ & $2(0.1)$ & $4(0.2)$ & .805 \\
\hline Neurological deficit persisting at discharge & $8(0.2)$ & $1(0.1)$ & $7(0.3)$ & .061 \\
\hline Phrenic nerve paralysis & $6(0.2)$ & $1(0.1)$ & $5(0.2)$ & .156 \\
\hline Mediastinitis & $21(0.5)$ & $10(0.6)$ & $11(0.5)$ & .844 \\
\hline Deep wound infection & $12(0.3)$ & $6(0.3)$ & $6(0.3)$ & .753 \\
\hline Median postoperative length of stay, (25th-75th percentile), d & $13(9-17)$ & $15(11-20)$ & $12(9-16)$ & $<.001$ \\
\hline
\end{tabular}

Data are presented as n (\%) except where otherwise noted. $V S D$, Ventricular septal defect; $B W$, body weight; $P M I$, pacemaker implantation. 